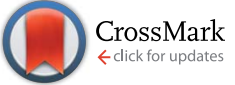

Cite this: RSC Adv., 2017, 7, 1241

\title{
Inhibition effect of aromatic aldehydes on butanol fermentation by Clostridium acetobutylicum
}

\begin{abstract}
Jing Li, ${ }^{a}$ Suan Shi, ${ }^{b}$ Sushil Adhikari ${ }^{\mathrm{a}}$ and Maobing $\mathrm{Tu}^{* \mathrm{c}}$
A large number of degradation compounds are formed during biomass pretreatment and they significantly inhibit the efficiency of biomass conversion to biofuels. Of those identified potential inhibitors, aromatic aldehydes play an important role in inhibition activity. Hence the effect of 13 aromatic aldehydes on acetone-butanol-ethanol (ABE) fermentation was assessed at four concentrations in the present work. It was found that the inhibition severity was affected by the ortho substituents $\left(\mathrm{OH}>\mathrm{OCH}_{3}>\mathrm{CHO}\right)$ and strongly related to the position of hydroxyl group instead of the number of hydroxyl groups. The orthohydroxyl group significantly contributed to the aromatic aldehyde inhibition. The ortho-substituted 2hydroxybenzaldehyde caused at least 20 -fold stronger inhibition than meta- and para-substituted analogues of 3- and 4-hydroxybenzaldehydes. The presence of ortho-hydroxyl group can form an intramolecular hydrogen bond with carbonyl hydrogen and potentially increase the cell membrane permeability and electrophilicity. Quantitative structure-activity relationship (QSAR) analysis was used to establish a correlation between inhibition activity $\left(\mathrm{IC}_{50}\right)$ and physicochemical descriptors. A strong correlation was observed between $\mathrm{IC}_{50}$ and the energy of the highest occupied molecular orbital $E_{\mathrm{HOMO}}$.
\end{abstract}

Received 23rd October 2016 Accepted 25th November 2016

DOI: 10.1039/c6ra25706b

www.rsc.org/advances
S. cerevisiae and their inhibition severity greatly depended on functional groups $\left(\mathrm{CH}=\mathrm{CH}, \mathrm{CHO}, \mathrm{OH}\right.$ and $\left.\mathrm{OCH}_{3}\right)$ attached to the benzene ring. Several model compounds were selected to be added into pure sugar fermentation, which aims to determine their potential inhibition on microbial fermentation. Ezeji et $a .^{8}{ }^{8}$ reported $3 \mathrm{~g} \mathrm{~L}^{-1}$ furfural or HMF was not inhibitory to $C$. beijerinckii BA101, instead they had a stimulation effect on cell growth and an improvement on ABE production was observed when furfural and HMF was up to $2 \mathrm{~g} \mathrm{~L}^{-1}$. They found ferulic acid and $p$-coumaric acid higher than $1 \mathrm{~g} \mathrm{~L} \mathrm{~L}^{-1}$ exhibited complete inhibition on cell growth and ABE production. Cho et $a{ }^{9}{ }^{9}$ investigated 6 phenolic compounds ( $p$-coumaric acid, ferulic acid, 4-hydroxybenzoic acid, vanillic acid, syringaldehyde, and vanillin) on butanol fermentation by Clostridium beijerinckii. They found little or no butanol was produced in the presence of $1 \mathrm{~g} \mathrm{~L}^{-1}$ of each compound. Cao et al. ${ }^{\mathbf{1 0}}$ found the growth of $T$. thermosaccharolyticum W16 and hydrogen production were stimulated by $5 \mathrm{~g} \mathrm{~L}^{-1}$ sodium acetate and negatively affected by further increasing concentration. On the contrary, the fermentation was completely inhibited by adding $1.8 \mathrm{~g} \mathrm{~L} \mathrm{~L}^{-1}$ syringaldehyde. Of these studies, the phenolic compounds had a significant inhibition on microbial growth and fermentation. Phenolic aldehydes and ketones mainly generated from lignin were considered more inhibitory than sugar-derived inhibitors. ${ }^{11}$ Although significant efforts have been made to demonstrate the effect of potential inhibitors on model fermentation, the comprehensive understanding of influence of chemical structure on microbial fermentation is lacking, particularly on ABE production. Our previous work

\footnotetext{
${ }^{a}$ Department of Biosystems Engineering, Auburn University, AL 36849, USA ${ }^{b}$ Hawaii Natural Energy Institute, University of Hawaii, Honolulu, HI 96822, USA ${ }^{c}$ Department of Biomedical, Chemical and Environmental Engineering, University of Cincinnati, Cincinnati, OH 45221, USA. E-mail: tumg@ucmail.uc.edu; Tel: +1 513 5562259
} 
found the aromatic aldehydes resulted in the most inhibitory impact on lactic acid fermentation. ${ }^{12}$ That is one of the reasons why we selected aromatic aldehydes to further assess their influence on butanol fermentation.

Considerable progress has been made to evaluate the impact of potential inhibitors but little is known about the mechanism of inhibition. Effective evidence is lacking although the hydrophobicity has been reported to correlate with phenol toxicity. The phenols were most likely responsible for increasing the fluidity of membrane and consequently affected the membrane permeability. ${ }^{11,13,14}$ The complexity of prehydrolysates made the study of mechanism much difficult. Quantitative structure-activity relationships (QSAR) analysis is helpful to address this issue. Although it has been successfully used in pharmacology and environmental toxicity assessment, ${ }^{15-18}$ little attention was paid in the field of biofuels production from biomass. The biological toxicity can be understood by association chemical structural properties with their inhibition activities, through which we can also predict their inhibition towards microbial fermentation. The molecular descriptors typically used for QSAR include octanol/ water partition coefficient $(\log P)$, energy of the lowest unoccupied molecular orbital ( $\left.E_{\mathrm{LUMO}}\right)$, energy of the highest occupied molecular orbital ( $\left.E_{\text {HомO}}\right)$, molar refractivity (MR), dipole moment $(u)$, and electrophilicity index $(\omega) .{ }^{\mathbf{1 9 , 2 0}}$

In the present study we selected 13 aromatic aldehydes and added them individually into butanol fermentation by $C$. acetobutylicum. The objectives of this work were (1) to understand the effects of aromatic aldehydes structure (substitution group, hydroxyl group position and amount of hydroxyl group) on $\mathrm{ABE}$ fermentation; and (2) to establish relationship between physicochemical properties and inhibition towards butanol fermentation.

\section{Experimental}

\section{Chemicals}

Glucose (anhydrous), 2,4-dihydroxybenzaldehyde and thiamine were purchased from Alfa Aesar (Ward Hill, MA). 4-Hydroxybenzaldehyde, vanillin and 2,3,4-trihydroxybenzaldehyde were purchased from Acros Organics (Morris Plains, NJ). o-Phthalaldehyde was purchased from Pickering Laboratories (Mountain View, CA). 2,3-Dihydroxybenzaldehyde, 3,4,5trihydroxybenzaldehyde, $o$-vanillin and 2-methoxybenzaldehyde were obtained from TCI America (Portland, OR). 2-Hydroxybenzaldehyde, 3-hydroxybenzaldehyde, $\mathrm{NH}_{4} \mathrm{Ac}$ and $p$-aminobenzoic acid were purchased from Alfa Aesar (Heysham, England). $\mathrm{NaCl}$ was purchased from VWR (Radnor, PA). 3,5Dihydroxybenzaldehyde, benzaldehyde and biotin were purchased from Sigma-Aldrich (St. Louis, MO). Reinforced Clostridial Medium (RCM) was purchased from HIMEDIA laboratories (Mumbai, India). $\mathrm{K}_{2} \mathrm{HPO}_{4}, \mathrm{KH}_{2} \mathrm{PO}_{4}, \mathrm{MgSO}_{4} \cdot 7 \mathrm{H}_{2} \mathrm{O}$, $\mathrm{MnSO}_{4} \cdot \mathrm{H}_{2} \mathrm{O}$ and $\mathrm{FeSO}_{4} \cdot 7 \mathrm{H}_{2} \mathrm{O}$ were obtained from Fisher Scientific (Fair Lawn, NJ). $\mathrm{CaCO}_{3}$ was supplied from EMD chemicals (Gibbstown, NJ). All chemical reagents were of chromatographic grades. DI-water was produced by the Barnstead Nanopure UV Ultrapure Water System (Thermo Fisher Scientific, Marietta, $\mathrm{OH}$ ).

\section{Microorganism and culture}

Clostridium acetobutylicum (ATCC 824) was kindly provided by Dr Y. Y. Lee of Chemical Engineering, Auburn University. It was stored as spores at $4{ }^{\circ} \mathrm{C}$ and treated by heat shock at $75{ }^{\circ} \mathrm{C}$ for $10 \mathrm{~min}$ and then cooled down in ice bath prior to cultivation. Reinforced Clostridial Medium (RCM) was used to cultivate the strain. It was bubbled through nitrogen for $15 \mathrm{~min}$ to remove the oxygen and then autoclaved at $121^{\circ} \mathrm{C}$ for $15 \mathrm{~min}$. The heatshocked cells were grown in RCM medium as seed inoculum until the optical density (OD) reached 1.30 determined by an UV-vis spectrometer at $600 \mathrm{~nm}$.

\section{Fermentation and inhibition study}

Fermentation was carried out in $125 \mathrm{~mL}$ serum bottle with working volume of $50 \mathrm{~mL}$ at $35^{\circ} \mathrm{C}$ and $80 \mathrm{rpm}$. To evaluate the effect of aromatic aldehydes, each inhibitor at four concentrations was added into P2 medium sterilized by filtration through a $0.2 \mu \mathrm{m}$ membrane filter. $0.25 \mathrm{M}$ stock of 2,3-dihydroxybenzaldehyde, 2,4-dihydroxybenzaldehyde, 2,3,4-trihydroxybenzaldehyde and $o$-vanillin were prepared and the other inhibitors tested were used as received. The P2 medium stock was prepared at high concentration. It contained mineral $\left(\mathrm{MgSO}_{4} \cdot 7 \mathrm{H}_{2} \mathrm{O} 40 \mathrm{~g} \mathrm{~L}^{-1}, \mathrm{MnSO}_{4} \cdot \mathrm{H}_{2} \mathrm{O} 2 \mathrm{~g} \mathrm{~L}^{-1}, \mathrm{FeSO}_{4} \cdot 7 \mathrm{H}_{2} \mathrm{O} 2 \mathrm{~g}\right.$ $\mathrm{L}^{-1}$ and $\left.\mathrm{NaCl} 2 \mathrm{~g} \mathrm{~L}^{-1}\right)$, buffer $\left(\mathrm{KH}_{2} \mathrm{PO}_{4} 50 \mathrm{~g} \mathrm{~L}^{-1}, \mathrm{~K}_{2} \mathrm{HPO}_{4} 50 \mathrm{~g} \mathrm{~L}^{-1}\right.$ and $\mathrm{NH}_{4} \mathrm{Ac} 220 \mathrm{~g} \mathrm{~L}^{-1}$ ) and vitamin (p-aminobenzoic acid $1 \mathrm{~g}$ $\mathrm{L}^{-1}$, thiamine $1 \mathrm{~g} \mathrm{~L}^{-1}$ and biotin $\left.0.01 \mathrm{~g} \mathrm{~L}^{-1}\right) .0 .25 \mathrm{~mL}$ mineral, $0.5 \mathrm{~mL}$ buffer and $0.05 \mathrm{~mL}$ vitamin solution were added into 45 $\mathrm{mL}$ water along with glucose at final concentration of $60 \mathrm{~g} \mathrm{~L}^{-1}$. $0.25 \mathrm{~g} \mathrm{CaCO}_{3}$ was supplemented to well control the $\mathrm{pH}$ during fermentation. The oxygen in medium was then purged out by a nitrogen purging system. The purging circle was repeated 7 times with each circle lasting 5 minutes. A $10 \%(\mathrm{v} / \mathrm{v})$ seed inoculum was transferred into P2 medium throughout the inhibition studies. Glucose control without adding any inhibitor was performed with every batch as reference fermentation. All the fermentation experiments were conducted in duplicates.

$50 \%$ butanol production inhibition concentration $\left(\mathrm{IC}_{50}\right)$ was calculated to quantify the inhibition effect of the thirteen compounds. Butanol production was found to be linearly related to the concentrations of tested aromatic aldehydes. $\mathrm{IC}_{50}$ represents the concentration of aromatic aldehydes resulting in final butanol concentration $50 \%$ of control and the four concentrations of test compounds were selected to cover this point. The lower the value of $\mathrm{IC}_{50}$, the higher is the inhibition of aromatic aldehydes.

\section{Calculation of physicochemical descriptors and statistical analysis}

Hydrophobicity $(\log P)$ and molecular refractivity were calculated by MarvinSketch. $E_{\mathrm{LUMO}}, E_{\mathrm{HOMO}}$, dipole moment $(u)$ and partial charge of the carbonyl carbon in aromatic aldehyde $\left(C^{\prime}\right.$ carb) were estimated by Gauss 9.0 and GaussView 5.0. The molecular electrophilicity index $(\omega)$ was calculated as described previously. ${ }^{\mathbf{1 2}}$ Correlations between physiochemical parameters and inhibition activity were carried out by regression analysis 
using Origin 8.5. The statistical values include: $n$ the number of observations, $s$ the standard error of the estimate, $r^{2}$ the coefficient of determination, $F$ Fisher statistic, and $p$ the significance. A value of $p<0.05$ indicated that the correlation was significant.

\section{HPLC analysis}

Glucose, acetic acid, butyric acid, ethanol, acetone and butanol were quantified by a HPLC system (Shimadzu LC-20A) equipped with an autosampler, LC-20 AD pump, and RID-10A detector, with a $300 \times 7.8 \mathrm{~mm}$ i.d., $9 \mu \mathrm{m}$, Aminex HPX-87H column, and a $30 \times 4.6 \mathrm{~mm}$ i.d. guard column of the same material (Bio-Rad, Hercules, CA). The mobile phase was composed of $5 \mathrm{mM}$ of sulfuric acid running isocratic at $0.6 \mathrm{~mL} \mathrm{~min}^{-1}$. The column temperature was maintained at $45{ }^{\circ} \mathrm{C}$ throughout the run.

\section{Results and discussions}

\section{Inhibition effects of aromatic aldehydes on butanol production}

To examine the inhibition effect of aromatic aldehydes on butanol fermentation, thirteen aromatic aldehydes with different substitution group $\left(\mathrm{OH}, \mathrm{CHO}\right.$ and $\left.\mathrm{OCH}_{3}\right)$ were added into fermentation by $C$. acetobutylicum. The structures are shown in Fig. 1. Overall, the inhibition activities of these compounds were dose dependent but the range at which the compounds showed their inhibition were quite different. Some aldehydes exhibited their inhibition at extremely low concentrations, while others did not show any inhibition at high concentrations (Table 1). Moreover, these aldehydes delayed the fermentation start time but not affecting the final butanol concentration at lower concentration and inhibited the butanol production only when the concentration is further increased.

The glucose control without adding any inhibitors produced $9.8 \mathrm{~g} \mathrm{~L}^{-1}$ butanol at $96 \mathrm{~h}$ with butanol yield of $0.17 \mathrm{~g} \mathrm{~g}^{-1}$ glucose and the butanol production rate at the exponential phase was $0.25 \mathrm{~g} \mathrm{~L}^{-1} \mathrm{~h}^{-1}$. The benzaldehyde did not inhibit the butanol production at 5.0 and $7.5 \mathrm{mM}$, but resulted in an extension of fermentation start time from $0 \mathrm{~h}$ (control) to 12 and $24 \mathrm{~h}$ respectively. When it increased to 10.0 and $12.5 \mathrm{mM}$ the final butanol concentration was reduced by $25 \%$ and $92 \%$ and the fermentation start time extended to 36 and $72 \mathrm{~h}$ respectively. Meanwhile, the butanol production rate was decreased accordingly (30\% and $70 \%$ at 10.0 and $12.5 \mathrm{mM}$ respectively). Similarly, addition of 3-hydroxybenzaldehyde and 4-hydroxybenzaldehyde did not or lightly inhibit final butanol production at low concentration (3-hydroxybenzaldehyde at 5.0 and $7.5 \mathrm{mM}$ and 4-hydroxybenzaldehyde at 2.5 and $5.0 \mathrm{mM}$ ), but significantly reduced final butanol concentration and productivity when the concentration reached high levels (3-hydroxybenzaldehyde at 8.5 and $10.0 \mathrm{mM}$ and 4-hydroxybenzaldehyde at 10.0 and $15.0 \mathrm{mM}$ ) and gradually extended the fermentation<smiles>O=Cc1ccccc1</smiles><smiles>O=Cc1ccccc1O</smiles><smiles>O=Cc1cccc(O)c1O</smiles><smiles>O=Cc1ccc(O)cc1O</smiles><smiles>O=Cc1ccc(O)c(O)c1O</smiles>

Benzaldehyde 2-hydroxybenzaldehyde 2,3-dihydroxybenzaldehyde 2,4-dihydroxybenzaldehyde 2,3,4-trihydroxybenzaldehyde<smiles>O=Cc1cccc(O)c1</smiles><smiles>O=Cc1cc(O)cc(O)c1</smiles><smiles>O=Cc1cc(O)c(O)c(O)c1</smiles><smiles>O=Cc1ccc(O)cc1</smiles>

3-hydroxybenzaldehyde<smiles>COc1cc(C=O)ccc1O</smiles><smiles>COc1cccc(C=O)c1O</smiles><smiles>COc1ccccc1C=O</smiles><smiles>O=Cc1ccccc1C=O</smiles>

4-hydroxy-3-methoxybenzaldehyde 2-hydroxy-3-methoxybenzaldehyde 2-methoxybenzaldehyde (vanillin) (o-vanillin)

(OPA)

Fig. 1 Structure of tested aromatic aldehydes. 
Table 1 Effects of aromatic aldehydes on butanol fermentation ${ }^{g}$

\begin{tabular}{|c|c|c|c|c|c|c|c|}
\hline Compounds & $\begin{array}{l}\text { Concentration } \\
(\mathrm{mM})\end{array}$ & $\begin{array}{l}C_{\text {butanol }^{a}} \\
\left(\mathrm{~g} \mathrm{~L}^{-1}\right)\end{array}$ & $C_{\mathrm{ABE}}^{b}\left(\mathrm{~g} \mathrm{~L}^{-1}\right)$ & $Y_{\text {butanol }}^{c}\left(\mathrm{~g} \mathrm{~g}^{-1}\right)$ & $Y_{\mathrm{ABE}}^{d}\left(\mathrm{~g} \mathrm{~g}^{-1}\right)$ & $Q_{\text {butanol }}^{e}\left(\mathrm{~g} \mathrm{~L}^{-1} \mathrm{~h}^{-1}\right)$ & $T_{\mathrm{s}}^{f}(\mathrm{~h})$ \\
\hline Control & 0.00 & $9.80 \pm 0.36$ & $13.74 \pm 0.45$ & $0.17 \pm 0.01$ & $0.24 \pm 0.01$ & $0.25 \pm 0.02$ & 0 \\
\hline & 7.5 & $9.85 \pm 0.50$ & $14.21 \pm 0.52$ & $0.18 \pm 0.01$ & $0.25 \pm 0.01$ & $0.21 \pm 0.01$ & 24 \\
\hline & 10.0 & $7.52 \pm 0.74$ & $10.86 \pm 0.78$ & $0.13 \pm 0.01$ & $0.18 \pm 0.01$ & $0.16 \pm 0.02$ & 36 \\
\hline & 12.5 & $0.79 \pm 0.17$ & $0.91 \pm 0.31$ & $0.01 \pm 0.00$ & $0.02 \pm 0.01$ & $0.07 \pm 0.01$ & 72 \\
\hline & 0.35 & $5.98 \pm 0.60$ & $8.19 \pm 0.61$ & $0.11 \pm 0.01$ & $0.15 \pm 0.02$ & $0.10 \pm 0.00$ & 36 \\
\hline & 0.5 & $2.76 \pm 0.60$ & $3.85 \pm 0.91$ & $0.05 \pm 0.01$ & $0.07 \pm 0.02$ & $0.08 \pm 0.00$ & 48 \\
\hline \multirow[t]{4}{*}{ 2,3-Dihydroxybenzaldehyde } & 0.1 & $9.54 \pm 0.02$ & $13.60 \pm 0.12$ & $0.17 \pm 0.00$ & $0.24 \pm 0.01$ & $0.19 \pm 0.01$ & 12 \\
\hline & 0.25 & $8.25 \pm 0.56$ & $11.65 \pm 0.79$ & $0.15 \pm 0.02$ & $0.21 \pm 0.02$ & $0.13 \pm 0.00$ & 24 \\
\hline & 0.35 & $1.17 \pm 0.08$ & $1.48 \pm 0.01$ & $0.02 \pm 0.00$ & $0.03 \pm 0.00$ & $0.05 \pm 0.00$ & 60 \\
\hline & 0.5 & $0.00 \pm 0.00$ & $0.00 \pm 0.00$ & $0.00 \pm 0.00$ & $0.00 \pm 0.00$ & $0.00 \pm 0.00$ & $>96$ \\
\hline \multirow[t]{4}{*}{ 2,3,4-Trihydroxybenzaldehyde } & 0.25 & $9.86 \pm 0.07$ & $13.74 \pm 0.07$ & $0.17 \pm 0.00$ & $0.23 \pm 0.00$ & $0.19 \pm 0.01$ & 12 \\
\hline & 0.5 & $8.83 \pm 0.03$ & $12.03 \pm 0.05$ & $0.15 \pm 0.00$ & $0.20 \pm 0.00$ & $0.12 \pm 0.00$ & 12 \\
\hline & 1.0 & $4.41 \pm 0.18$ & $6.13 \pm 0.15$ & $0.08 \pm 0.00$ & $0.10 \pm 0.00$ & $0.07 \pm 0.00$ & 36 \\
\hline & 1.5 & $0.00 \pm 0.00$ & $0.00 \pm 0.00$ & $0.00 \pm 0.00$ & $0.00 \pm 0.00$ & $0.00 \pm 0.00$ & $>96$ \\
\hline \multirow[t]{4}{*}{ 3-Hydroxybenzaldehyde } & 5.0 & $9.75 \pm 0.27$ & $13.80 \pm 0.30$ & $0.17 \pm 0.00$ & $0.24 \pm 0.00$ & $0.20 \pm 0.01$ & 12 \\
\hline & 7.5 & $9.41 \pm 0.47$ & $13.90 \pm 0.54$ & $0.16 \pm 0.00$ & $0.24 \pm 0.00$ & $0.16 \pm 0.01$ & 24 \\
\hline & 8.5 & $5.44 \pm 0.06$ & $7.48 \pm 0.00$ & $0.09 \pm 0.00$ & $0.13 \pm 0.00$ & $0.12 \pm 0.00$ & 36 \\
\hline & 10.0 & $2.88 \pm 0.41$ & $3.62 \pm 0.62$ & $0.05 \pm 0.01$ & $0.06 \pm 0.01$ & $0.08 \pm 0.01$ & 48 \\
\hline \multirow[t]{4}{*}{ 3,5-Dihydroxybenzaldehyde } & 2.5 & $9.40 \pm 0.41$ & $13.76 \pm 0.43$ & $0.16 \pm 0.01$ & $0.23 \pm 0.01$ & $0.16 \pm 0.00$ & 12 \\
\hline & 5.0 & $9.05 \pm 0.32$ & $13.37 \pm 0.39$ & $0.15 \pm 0.01$ & $0.22 \pm 0.01$ & $0.10 \pm 0.00$ & 12 \\
\hline & 7.5 & $0.00 \pm 0.00$ & $0.02 \pm 0.00$ & $0.00 \pm 0.00$ & $0.00 \pm 0.00$ & $0.00 \pm 0.00$ & 72 \\
\hline & 8.5 & $0.00 \pm 0.00$ & $0.00 \pm 0.00$ & $0.00 \pm 0.00$ & $0.00 \pm 0.00$ & $0.00 \pm 0.00$ & $>96$ \\
\hline \multirow[t]{4}{*}{ Vanillin } & 2.5 & $7.00 \pm 0.21$ & $9.43 \pm 0.58$ & $0.12 \pm 0.00$ & $0.17 \pm 0.01$ & $0.17 \pm 0.01$ & 0 \\
\hline & 5.0 & $6.00 \pm 0.52$ & $8.23 \pm 0.79$ & $0.10 \pm 0.01$ & $0.14 \pm 0.01$ & $0.07 \pm 0.01$ & 0 \\
\hline & 15.0 & $4.85 \pm 0.30$ & $6.69 \pm 0.73$ & $0.09 \pm 0.01$ & $0.12 \pm 0.00$ & $0.06 \pm 0.00$ & 12 \\
\hline & 25.0 & $0.25 \pm 0.07$ & $0.24 \pm 0.07$ & $0.004 \pm 0.00$ & $0.004 \pm 0.01$ & $0.01 \pm 0.01$ & 36 \\
\hline \multirow[t]{4}{*}{$o$-Vanillin } & 0.5 & $10.77 \pm 0.43$ & $15.45 \pm 0.68$ & $0.19 \pm 0.00$ & $0.27 \pm 0.01$ & $0.20 \pm 0.01$ & 12 \\
\hline & 0.65 & $3.77 \pm 0.05$ & $4.62 \pm 0.04$ & $0.07 \pm 0.00$ & $0.09 \pm 0.00$ & $0.10 \pm 0.00$ & 36 \\
\hline & 0.7 & $1.05 \pm 0.53$ & $1.43 \pm 0.56$ & $0.03 \pm 0.01$ & $0.02 \pm 0.01$ & $0.08 \pm 0.04$ & 72 \\
\hline & 0.8 & $0.00 \pm 0.00$ & $0.00 \pm 0.00$ & $0.00 \pm 0.00$ & $0.00 \pm 0.00$ & $0.00 \pm 0.00$ & $>96$ \\
\hline \multirow[t]{4}{*}{ 2-Methoxybenzaldehyde } & 2.5 & $9.74 \pm 0.06$ & $13.75 \pm 0.10$ & $0.17 \pm 0.01$ & $0.25 \pm 0.01$ & $0.21 \pm 0.00$ & 12 \\
\hline & 3.5 & $9.86 \pm 0.14$ & $13.97 \pm 0.34$ & $0.18 \pm 0.00$ & $0.25 \pm 0.00$ & $0.20 \pm 0.01$ & 12 \\
\hline & 5.0 & $7.80 \pm 0.82$ & $10.94 \pm 0.67$ & $0.14 \pm 0.01$ & $0.19 \pm 0.01$ & $0.17 \pm 0.02$ & 48 \\
\hline & 6.0 & $0.00 \pm 0.00$ & $0.00 \pm 0.00$ & $0.00 \pm 0.00$ & $0.00 \pm 0.00$ & $0.00 \pm 0.00$ & 84 \\
\hline \multirow[t]{4}{*}{$o$-Phthalaldehyde (OPA) } & 12.5 & $8.72 \pm 0.32$ & $12.33 \pm 0.90$ & $0.15 \pm 0.01$ & $0.21 \pm 0.02$ & $0.17 \pm 0.00$ & 12 \\
\hline & 15.0 & $7.48 \pm 0.25$ & $11.11 \pm 0.54$ & $0.13 \pm 0.00$ & $0.19 \pm 0.01$ & $0.12 \pm 0.00$ & 24 \\
\hline & 17.5 & $5.36 \pm 0.32$ & $8.04 \pm 0.53$ & $0.09 \pm 0.01$ & $0.14 \pm 0.01$ & $0.08 \pm 0.01$ & 24 \\
\hline & 20.0 & $3.59 \pm 0.01$ & $5.31 \pm 0.00$ & $0.06 \pm 0.00$ & $0.09 \pm 0.00$ & $0.07 \pm 0.00$ & 36 \\
\hline
\end{tabular}

${ }^{a} C_{\text {butanol }}$ butanol concentration at 96 h. ${ }^{b} C_{\mathrm{ABE}} \mathrm{ABE}$ concentration at $96 \mathrm{~h} .{ }^{c} Y_{\text {butanol }}$ butanol yield at $96 \mathrm{~h}$ (g butanol per g original glucose). ${ }^{d} Y_{\mathrm{ABE}}$ ABE yield at $96 \mathrm{~h}$ (g butanol per $\mathrm{g}$ original glucose). ${ }^{e} Q_{\text {butanol }}$ volumetric butanol productivity at exponential phase. ${ }^{f} T_{\mathrm{s}}$ fermentation start time. ${ }^{g}$ The data were presented as mean value \pm standard deviation.

start time. In the case of vanillin, 3,5-dihydroxybenzaldehyde, 3,4,5-trihydroxybenzaldehyde and 2-methoxybenzaldehyde, butanol yield and productivity were decreased at lower concentration and the fermentation start time was increased dramatically. Moreover, addition of 2,4-dihydroxybenzaldehyde at 1.0 and $1.25 \mathrm{mM}$ and 2,3,4-trihydroxybenzaldehyde at 0.25 
and $0.5 \mathrm{mM}$ did not lead to reduction on butanol yield but lightly dropped on productivity. While when the concentration of them slightly increase to 2.0 and $1.5 \mathrm{mM}$, both butanol yield and butanol production rate considerably dropped by $88 \%$ and $100 \%$ of control respectively, indicating a strong inhibition of these two hydroxybenzaldehydes. An even more strong inhibition was observed by addition of 2-hydroxybenzaldehyde, 2,3dihydroxybenzaldehyde and $o$-vanillin. At 0.1 and $0.25 \mathrm{mM}, 2$ hydroxybenzaldehyde and 2,3-dihydroxybenzaldehyde did not inhibit final butanol yield, but the butanol productivity was found to be reduced (17\% reduction at $0.1 \mathrm{mM}$ and $48 \%$ reduction at $0.25 \mathrm{mM}$ ) as well as the fermentation start time was extended to $12 \mathrm{~h}$ and $24 \mathrm{~h}$ by adding 2,3-dihydroxybenzaldehyde at $0.1 \mathrm{mM}$ and $0.25 \mathrm{mM}$. When the concentration was only further increased to $0.5 \mathrm{mM}, 2$-hydroxybenzaldehyde inhibited the fermentation by decreasing butanol yield to $29 \%$ of control and butanol productivity to $32 \%$ of control; 2,3-dihydroxybenzaldehyde terminated the fermentation with no production of butanol. Likewise, $o$-vanillin partially inhibited the fermentation at 0.65 and $0.7 \mathrm{mM}$ but completely stopped the butanol production at $0.8 \mathrm{mM}$. Interestingly, $o$-vanillin and benzaldehydehyde were observed to slightly improve butanol yield by $12 \%$ and $6 \%$ at 0.5 and $5.0 \mathrm{mM}$ respectively. The similar results were reported by our previous work and literature, ${ }^{\mathbf{8 , 2 1 , 2 2}}$ it was found that the fuels and chemicals production could be enhanced by furfural, HMF and vanillin at low concentrations. In the case of $o$-phthalaldehyde (OPA), it decreased the butanol yield by $12 \%$ when the concentration was as high as $12.5 \mathrm{mM}$ and further decreased it by $65 \%$ with the concentration increasing to $20 \mathrm{mM}$. It was different from that in lactic acid fermentation which resulted in a very strong inhibition. ${ }^{\mathbf{1 2}}$ This difference was probably due to that difference strain and media used in two processes.

Aromatic aldehyde derived from lignin is a large group of degradation compounds found in lignocellulosic prehydrolysates. The species of these aromatic monomers depends on the type of pretreatment and the $\mathrm{H} / \mathrm{G} / \mathrm{S}$ ratio of lignin present in the feedstocks. Benzaldehyde with various numbers of hydroxyl groups and methoxyl groups attached to different positions in benzene ring were identified in biomass hydrolysates from a variety of pretreatments. ${ }^{4,7,23}$ Vanillin was reported to be at high concentration in corn stover, poplar and pine hydrolysates. The corn stover hydrolysates contains higher amount of 4-hydroxybenzaldehyde than hydrolysates of poplar and pine. ${ }^{4}$ Some of these identified compounds were investigated in this work. The other compounds that have not been reported to be present in hydrolysates were also investigated in this study. This was aimed to achieve a comprehensive understanding on the effect of chemical structure on their inhibition behavior.

\section{Influence of ortho substituents on butanol production}

Since hydroxyl $(\mathrm{OH})$, methoxyl $\left(\mathrm{OCH}_{3}\right)$ and aldehyde (CHO) groups are commonly present in the prehydrolysates, they were selected for the purpose to understand how they affect the fermentation by C. acetobutylicum (Table 1 and Fig. 2). The

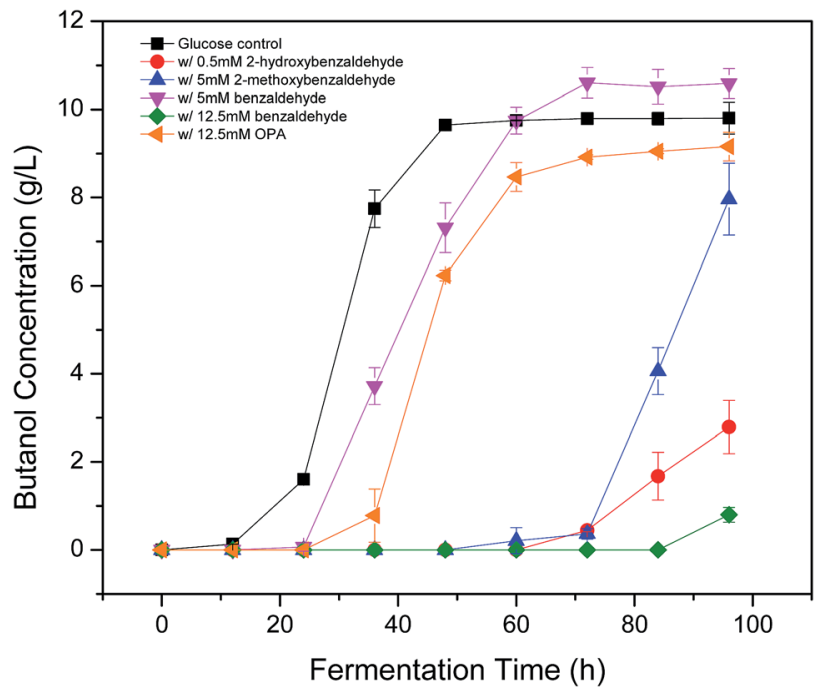

Fig. 2 Effect of ortho substituents on butanol production.

benzaldehyde without $\mathrm{OH}$ group at $5 \mathrm{mM}$ did not inhibit final butanol concentration compared to the control but improved it by $8 \%$ instead. While it decreased butanol production rate and increased the fermentation start time by $12 \mathrm{~h}$. At the same concentration, 2-methoxybenzaldehyde inhibited final butanol concentration and yield by $20 \%$ and $18 \%$, respectively (Fig. 2). Moreover, at $0.5 \mathrm{mM}, 2$-hydroxybenzaldehyde significantly reduced final butanol concentration by $72 \%$ and delayed the fermentation by $48 \mathrm{~h}$ (Fig. 2). Meanwhile, we compared $o$ phthalaldehyde (OPA) with benzaldehyde at $12.5 \mathrm{mM}$. It was shown that the benzaldehyde at this concentration significantly inhibited final butanol concentration to $0.79 \mathrm{~g} \mathrm{~L} \mathrm{~L}^{-1}$ and increased the lag phase to $72 \mathrm{~h}$ while $o$-phthalaldehyde (OPA) only decreased the final butanol concentration to $8.72 \mathrm{~g} \mathrm{~L}^{-1}$ (89\% of control) and the fermentation start time was only increased to $12 \mathrm{~h}$ (Table 1 and Fig. 2). Therefore, these results suggested the inhibition of ortho-substituents followed: ortho$\mathrm{OH}>$ ortho $-\mathrm{OCH}_{3}>$ no ortho substituent $>$ ortho-CHO.

\section{Influence of hydroxyl group positions on butanol production}

Phenolic compounds are often present in the prehydrolysates after pretreatment, ${ }^{1,24,25}$ so it is essential to know how the hydroxyl groups in aromatic compounds affect their inhibition including the positions and amount of hydroxyl group. It was found that 2-hydroxybenzaldehyde showed strong inhibition even at only $0.5 \mathrm{mM}$ in the previous section, which increased fermentation start time to $48 \mathrm{~h}$ and decreased final butanol concentration to $2.76 \mathrm{~g} \mathrm{~L}^{-1}$ equivalent to $28 \%$ of the control (Fig. 3). While 3-hydroxybenzaldehyde and 4-hydroxybenzaldehyde, in which the hydroxyl group occupied meta- or para-position, lost the inhibition significantly. At twenty times higher concentration (10 mM), 3-hydroxybenzaldehyde exhibited a similar butanol production inhibition as 2-hydroxybenzaldehyde. And 4-hydroxybenzaldehyde (10 $\mathrm{mM})$ resulted in only $32 \%$ reduction in final butanol concentration (Fig. 3). These results indicated the hydroxyl group in ortho-position 


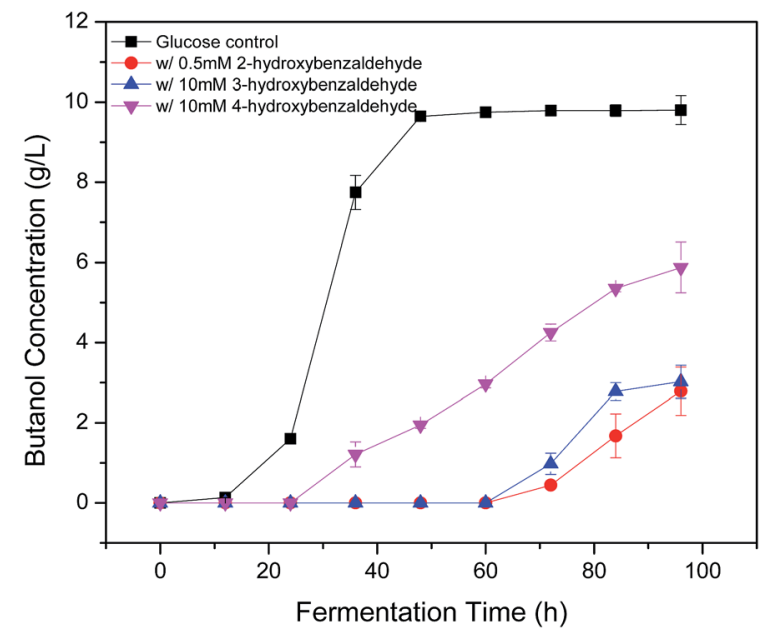

Fig. 3 Effect of hydroxyl group positions in benzaldehyde on butanol production.

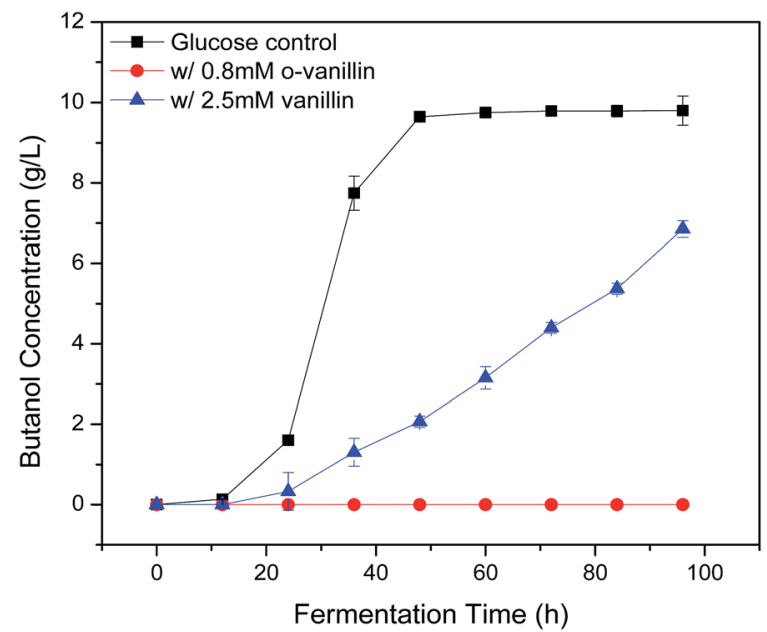

Fig. 4 Effect of hydroxyl group positions in methoxy-benzaldehyde on butanol production.

caused at least 20 -fold stronger inhibition than meta- and paraposition, and meta-position was more inhibitory than paraposition. The same effect was noticed with vanillin and $o$ vanillin. Vanillin at $2.5 \mathrm{mM}$ only reduced final butanol concentration and yield by $29 \%$, while $o$-vanillin at $0.8 \mathrm{mM}$ completely inhibited fermentation with no butanol produced (Fig. 4). Therefore, by examining the effect of hydroxyl group positions in both benzaldehyde and methoxy-benzaldehyde on butanol production, it was found that the inhibition of hydroxyl group followed the order of ortho- > meta- > para- and the ortho hydroxyl group inhibited butanol fermentation significantly.

\section{Influence of hydroxyl group number on butanol production}

After knowing the positions of hydroxyl group had an effect on butanol fermentation, we further investigated whether the hydroxyl group number in aromatic compounds had an influence on butanol production. Our study covered aromatic

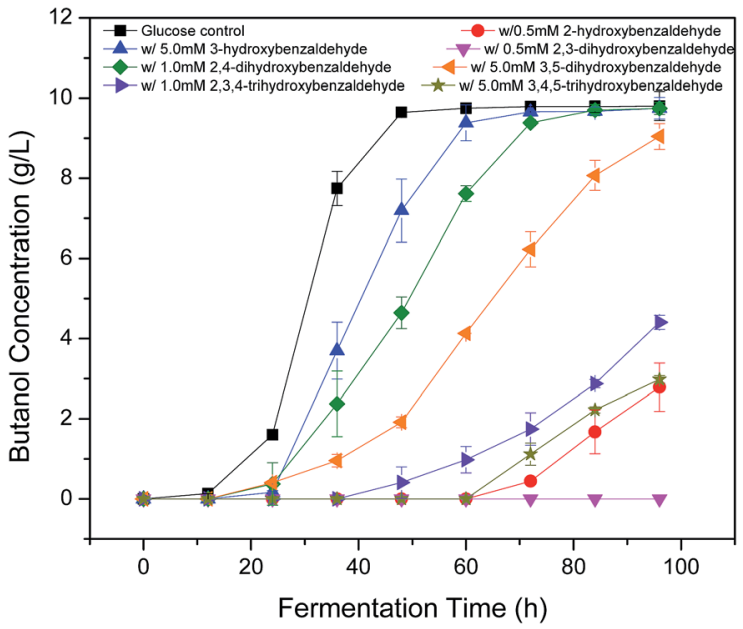

Fig. 5 Effect of hydroxyl group number on butanol production.

aldehydes with one, two and three hydroxyl groups, including 2hydroxybenzaldehyde, 3-hydroxybenzaldehyde, 2,3-dihydroxybenzaldehyde, 2,4-dihydroxybenzaldehyde, 3,5-dihydroxybenzaldehyde, 2,3,4-trihydroxybenzaldehyde and 3,4,5trihydroxybenzaldehyde. It was observed that 2-hydroxybenzaldehyde and 2,3-dihydroxybenzaldehyde at $0.5 \mathrm{mM}$ reduced final butanol concentration by $72 \%$ and $100 \%$, respectively (Fig. 5). It indicated 2,3-dihydroxybenzaldehyde which had two hydroxyl groups was more inhibitory. However, 2,4-dihydroxybenzaldehyde and 3,5-dihydroxybenzaldehyde also contained two hydroxyl groups, they decreased final butanol concentration by $1 \%$ and $8 \%$ at $1 \mathrm{mM}$ and $5 \mathrm{mM}$, respectively (Fig. 5). Moreover, addition with 2,3,4-trihydroxybenzaldehyde and 3,4,5-trihydroxybenzaldehyde at $1.0 \mathrm{mM}$ and $5.0 \mathrm{mM}$ had a higher final butanol concentration and yield than that with 2-hydroxybenzaldehyde at $0.5 \mathrm{mM}$ (Fig. 5). It appeared that more hydroxyl groups resulted in lower inhibition except 2,3-dihydroxybenzaldehyde. While in contrast, 3hydroxybenzaldehyde at $5 \mathrm{mM}$ almost showed no inhibition, which had the higher final butanol concentration, yield and productivity than all the other aldehydes with two or three hydroxyl groups at same or lower concentrations (Fig. 5). Hence, the number of hydroxyl groups did not contribute to the phenolic inhibition on butanol fermentation.

In order to quantify the inhibition effect of aromatic aldehydes, $50 \%$ butanol production inhibition concentration $\left(\mathrm{IC}_{50}\right)$ was calculated. It was defined as the inhibitor concentration at which the final butanol concentration was $50 \%$ of glucose control. Fig. 6 showed the $\mathrm{IC}_{50}$ value of tested compounds. The lower the value, the higher is the inhibitory effect. Interestingly, it was observed that all the compounds contained orthohydroxyl group had a very low $\mathrm{IC}_{50}$ value ranging from 0.29 to $1.47 \mathrm{mM}$, which were lower than any other aromatic aldehydes, indicating high inhibition activity. Similar observations have been reported recently on phenolic aldehyde inhibition on yeast fermentation. ${ }^{26}$ This severe inhibition was probably due to the ortho-hydroxyl group forming intramolecular hydrogen bond within the aromatic aldehydes and thus, it potentially increased 


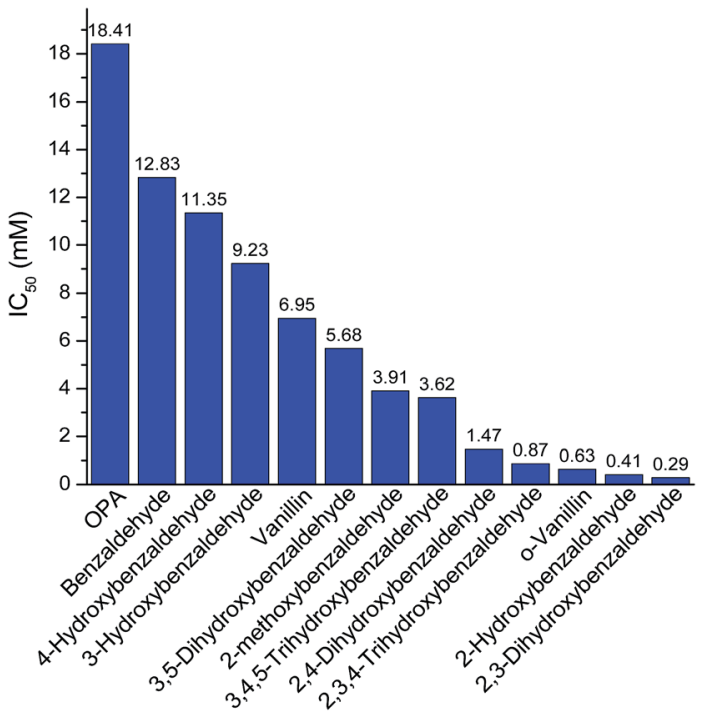

Fig. $6 \quad I C_{50}$ of examined aromatic benzaldehydes.

cell membrane permeability and electrophilicity. The strong inhibition caused by ortho $-\mathrm{OH}$ is also observed by other researchers. Friedman et al. ${ }^{27}$ investigated the activity of 35 benzaldehydes, 34 benzoic acids and 1 benzoic acid methyl ester on Campylobacter jejuni, Escherichia coli, Listeria monocytogenes, and Salmonella enterica and they found that nine of the ten compounds which were most active against four microbes contained ortho-hydroxyl group. In addition, it was found that compounds with $\mathrm{OH}$ groups were more active than that with $\mathrm{OCH}_{3}$ groups. A similar finding was reported by Larsson $e$ t al. ${ }^{28}$ and they noticed vanillin at $0.2 \mathrm{~g} \mathrm{~L}^{-1}$ was slightly inhibitory to ethanol formation and cell growth while $o$-vanillin at the same concentration resulted in complete inhibition.

\section{Inhibition effects of aromatic aldehydes on ABE and butyric acid production}

Butanol fermentation is also known as ABE fermentation since the other two solvents, acetone and ethanol were produced along with butanol by C. acetobutylicum. Thus, it is necessary to know how these aromatic compounds affect their production. It was found that the ABE final concentration at $96 \mathrm{~h}$ was dose dependent (Table 1 and Fig. 7). The glucose control without any inhibitors generated $13.74 \mathrm{~g} \mathrm{~L}^{-1} \mathrm{ABE}$ with a yield of $0.24 \mathrm{~g} \mathrm{~g}^{-1}$ glucose. Interestingly, similar to butanol production, benzaldehyde at 5.0 and $7.5 \mathrm{mM}$ and $o$-vanillin at $0.5 \mathrm{mM}$ improved ABE final concentration by $10 \%, 3 \%$ and $12 \%$, respectively.
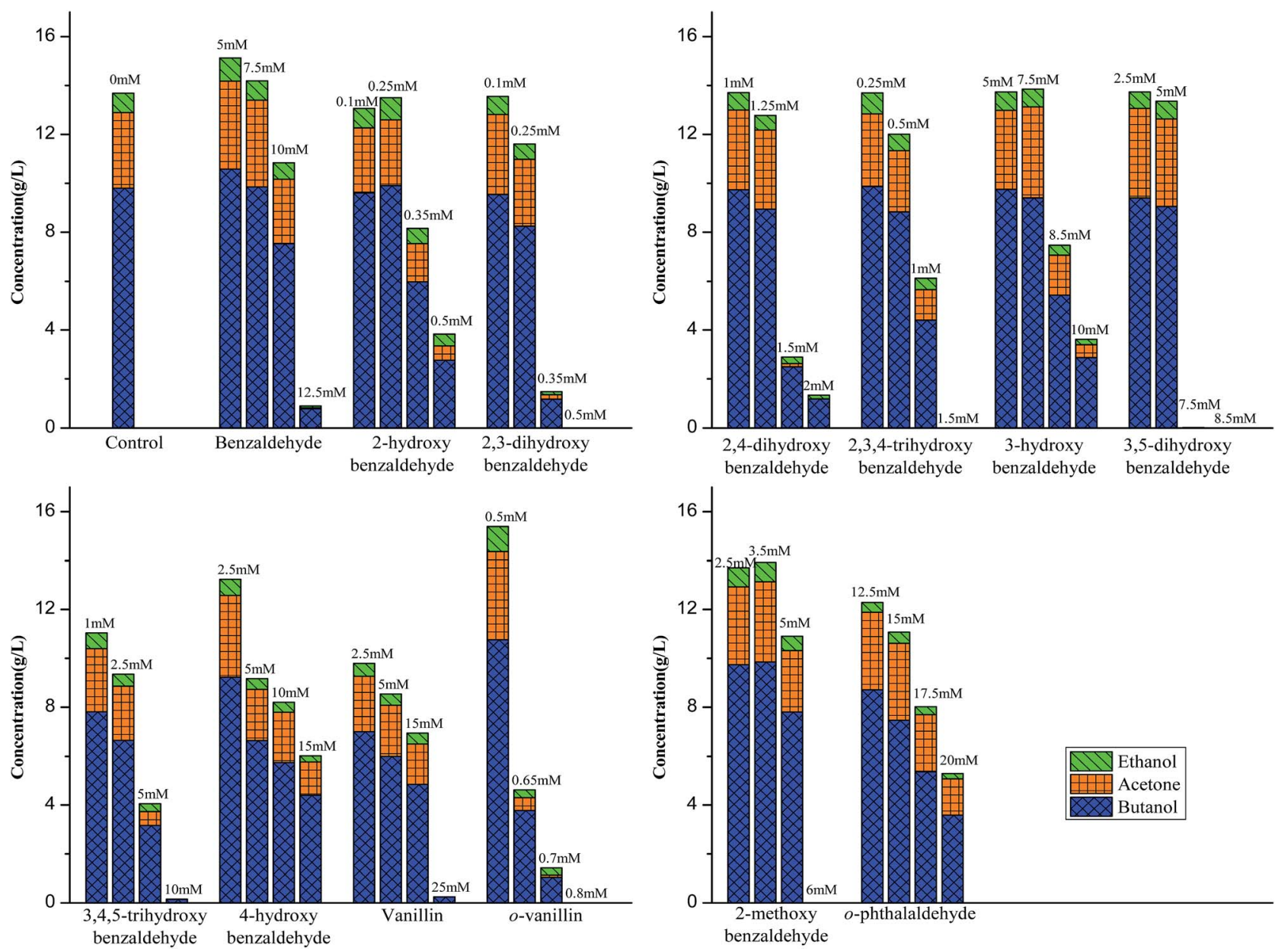

Fig. 7 Effect of aromatic aldehydes on ABE production. 
Table 2 Calculated physicochemical descriptors of aromatic aldehydes and their inhibition

\begin{tabular}{|c|c|c|c|c|c|c|c|c|}
\hline Compounds & $\log P$ & $E_{\text {LUMO }}(\mathrm{eV})$ & $E_{\text {номо }}(\mathrm{eV})$ & Dipole (debye) & MR & $\omega$ & $C_{c a r b}^{\prime}$ & $\mathrm{IC}_{50}(\mathrm{mM})$ \\
\hline Benzaldehyde & 1.69 & -0.88 & -10.09 & 4.53 & 32.64 & 3.27 & 0.431 & 12.83 \\
\hline 2-Hydroxybenzaldehyde & 2.03 & -0.91 & -9.61 & 6.53 & 34.62 & 3.18 & 0.471 & 0.41 \\
\hline 2,3-Dihydroxybenzaldehyde & 1.73 & -1.09 & -9.23 & 6.75 & 36.60 & 3.27 & 0.458 & 0.29 \\
\hline 2,4-Dihydroxybenzaldehyde & 1.73 & -0.83 & -9.70 & 5.91 & 36.60 & 3.13 & 0.485 & 1.47 \\
\hline 2,3,4-Trihydroxybenzaldehyde & 1.43 & -1.11 & -9.25 & 0.79 & 38.58 & 3.30 & 0.469 & 0.87 \\
\hline 3-Hydroxybenzaldehyde & 1.38 & -1.06 & -9.47 & 4.65 & 34.62 & 3.30 & 0.414 & 9.23 \\
\hline 3,5-Dihydroxybenzaldehyde & 1.08 & -0.92 & -9.44 & 6.04 & 36.60 & 3.15 & 0.404 & 5.68 \\
\hline 3,4,5-Trihydroxybenzaldehyde & 0.78 & -1.17 & -9.56 & 5.05 & 38.58 & 3.43 & 0.410 & 3.62 \\
\hline 4-Hydroxybenzaldehyde & 1.38 & -0.85 & -9.62 & 5.99 & 34.62 & 3.12 & 0.452 & 11.35 \\
\hline Vanillin & 1.22 & -1.01 & -9.14 & 6.41 & 41.09 & 3.17 & 0.435 & 6.95 \\
\hline$o$-Vanillin & 1.87 & -1.05 & -9.10 & 7.76 & 41.09 & 3.20 & 0.458 & 0.63 \\
\hline 2-Methoxybenzaldehyde & 1.53 & -0.87 & -9.45 & 7.09 & 39.11 & 3.10 & 0.471 & 3.91 \\
\hline$o$-Phthalaldehyde & 1.40 & -1.40 & -10.31 & 7.11 & 39.23 & 3.85 & 0.419 & 18.41 \\
\hline
\end{tabular}

Table 3 Regression analysis between $\mathrm{IC}_{50}$ and molecular descriptors

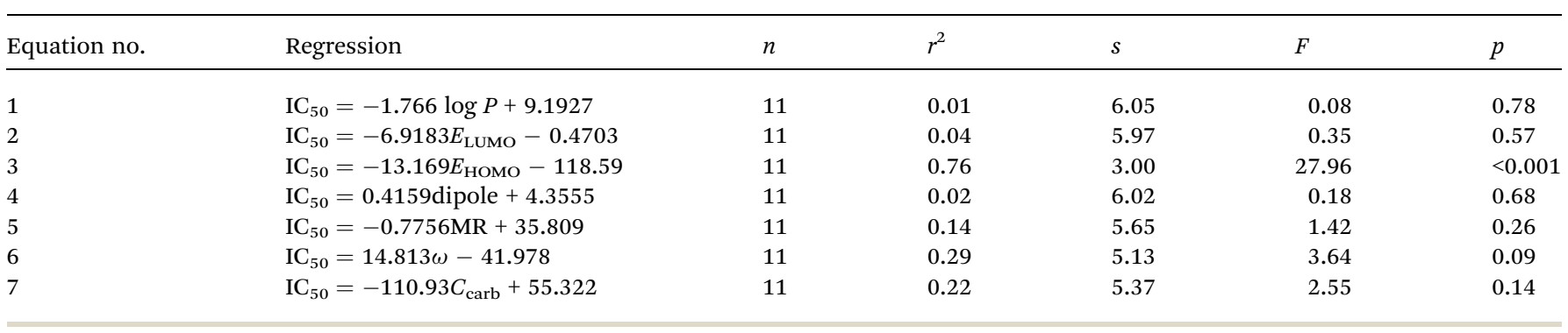

Particularly, it was observed that the aromatic aldehydes suppressed acetone, butanol and ethanol production proportionally. The distribution of acetone, butanol and ethanol was not changed by different compounds at various concentrations (Fig. 7). Butanol was the most one accounting for $67-73 \%$, acetone and ethanol took $24-27 \%$ and $5-8 \%$ respectively. It agreed with the previous report that the ratio of butanol, acetone, and ethanol was $6: 3: 1 .^{29}$ On the other hand, the acid production varied with the addition of different compounds and was not found in any trend with compounds at different concentrations. This was caused by the two phases involved in ABE fermentation, named acidogenic phase and solventogenic phase. The butyric acid accumulated during acidogenic phase and then re-entered into cells to form butanol at solventogenic phase, ${ }^{30,31}$ resulting in a peak concentration of butyric acid. The final acid concentration with adding certain compound is recorded at $96 \mathrm{~h}$ in this assay could be in acidogenic phase or solventogenic phase due to the delay caused by the compound. As a result, the determined acid concentration was potentially affected by both the enzymes activity in acidogenic and solventogenic phases, which could increase or decrease the acid concentration in either direction.

The finding of inhibition effect of aromatic aldehydes and the significant contribution of ortho-hydroxyl group to aromatic aldehydes inhibition could be used to suggest essential improvement on biofuels production. It has an important implication in detoxifying biomass hydrolysates, from which the cost-effective method could be developed. Meanwhile, generating less aldehydes is critical criteria when considering pretreatment types and conditions. The phenolic aldehydes and ketones have been observed to be favored at oxidative acid conditions $^{23}$ while the alkaline pretreatment tends to further oxidize the aldehydes/ketones to their corresponding acids. In addition, different microbes exhibit various tolerance to degradation compounds, this study indicated choosing aldehydes-resistant butanol producing bacteria or developing

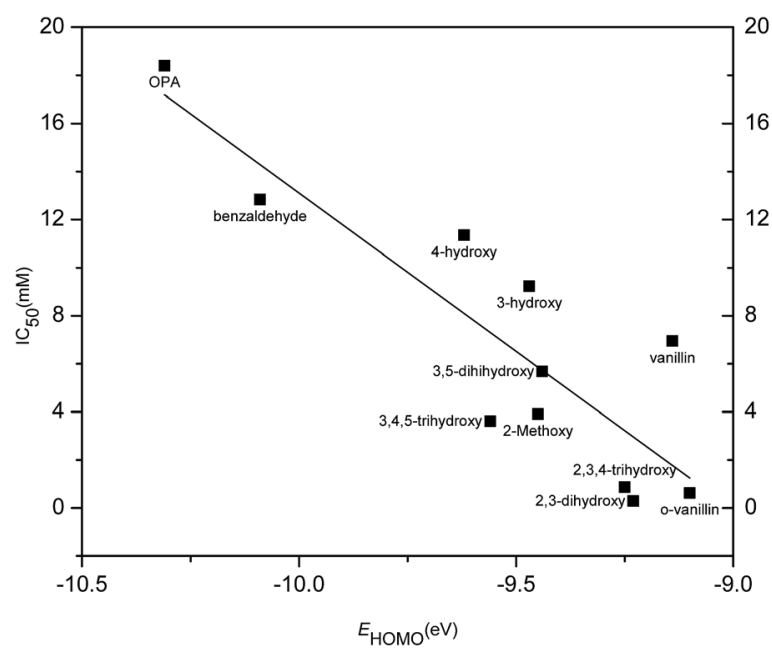

Fig. 8 Plot of $\mathrm{IC}_{50}$ versus $E_{\mathrm{HOMO}}$. 
gene modified strains would be beneficial to improve the butanol fermentation from lignocellulosic biomass.

\section{Quantitative structure-activity relationship (QSAR) analysis}

The inhibition activity $\left(\mathrm{IC}_{50}\right)$ of aromatic aldehydes on butanol fermentation was correlated with molecular descriptors as summarized in Tables 2 and 3. Among these calculated physicochemical descriptors, a significant linear relationship $\left(r^{2}=\right.$ $0.76, p<0.001$ ) was found between $\mathrm{IC}_{50}$ and $E_{\text {HOMO }}$ (energy of the highest occupied molecular orbital) (eqn (3) in Table 3 and

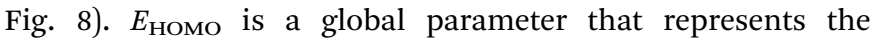
tendency to release electrons. The smaller the absolute value of $E_{\text {HOMO }}$, the stronger is the compounds' electron donor capacity. $\mathrm{IC}_{50}$ was negatively correlated to $E_{\text {номо }}$ suggesting the aromatic aldehydes with high $E_{\text {Hомо }}$ value resulted in high inhibition activity. 2,3-Dihydroxybenzaldehyde had a fairly high $E_{\text {Номо }}$ value and was observed to have the highest inhibition on butanol fermentation. The $E_{\text {Hомо }}$ of $o$-phthalaldehyde was the lowest among all the tested aromatic aldehydes and showed the lowest inhibition. This correlation suggested $E_{\text {номо could be }}$ used to predict the inhibition of phenolic compounds on butanol fermentation and also revealed the possible mechanism of inhibitors' toxicity.

Regression analysis showed $\log P, E_{\mathrm{LUMO}}$, dipole moment, molecular refractivity (MR), $\omega$, and $C^{\prime}$ carb did not have a linear relationship to the inhibition (Table 3). $\log P$ is a global parameter which measures the hydrophobicity of a molecule. ${ }^{32}$ We found a good linear correlation between inhibition constant and $\log P$ in lactic acid fermentation. ${ }^{12}$ However, it was not the case in butanol fermentation, and 2,3-dihydroxybenzaldehyde exhibited the highest inhibition with $\log P$ value of 1.73 , which did not show the highest hydrophobicity. This difference was probably caused by the different microorganisms and fermentation media, and the diffusion of compounds through cell membrane might not be the dominant step when the inhibitors interact with biological objects in butanol fermentation process.

\section{Conclusions}

The influence of thirteen aromatic aldehydes on ABE fermentation by $C$. acetobutylicum was evaluated. It was observed that their inhibition activity on butanol production was related to the ortho-substituted hydroxyl group $\left(\mathrm{OH}>\mathrm{OCH}_{3}>\mathrm{CHO}\right)$ and it was also affected by the position of hydroxyl group instead of the number of hydroxyl group. By examining the effect of hydroxyl group positions in both benzaldehyde and methoxybenzaldehyde on butanol production, it was observed that the inhibition of hydroxyl group followed the order of ortho- > meta$>$ para-. The ortho-hydroxyl group played an important role in the inhibition severity. It caused at least 20-fold stronger inhibition than meta- and para-position. Particularly, it was noticed that the ortho-hydroxyl group was present only in the top five most inhibitory compounds. The presence of ortho-hydroxyl group can form an intramolecular hydrogen bond with carbonyl hydrogen and potentially increase the cell membrane permeability and electrophilicity. In addition, the distribution of acetone, butanol and ethanol was not affected by these aromatic aldehydes. Butanol, acetone and ethanol accounted for $67-73 \%, 24-27 \%$ and $5-8 \%$, respectively. Quantitative structure-activity relationship (QSAR) analysis suggested a strong correlation $\left(r^{2}=0.76, p<0.001\right)$ between inhibition activity $\left(\mathrm{IC}_{50}\right)$ and energy of the highest occupied molecular orbital ( $\left.E_{\text {HOMO }}\right)$.

\section{Acknowledgements}

We gratefully acknowledge the financial support from National Science Foundation (NSF-CBET 1555633), Southeastern Sun Grant Center, United States Department of Agriculture (USDA2010-38502-21854), and the United States Department of Agriculture-National Institute of Food and Agriculture (USDANIFA) through the Integrated Biomass Supply Systems (IBSS) project (2011-68005-30410).

\section{Notes and references}

1 H. B. Klinke, A. Thomsen and B. K. Ahring, Appl. Microbiol. Biotechnol., 2004, 66, 10-26.

2 Y.-S. Jang, A. Malaviya, C. Cho, J. Lee and S. Y. Lee, Bioresour. Technol., 2012, 123, 653-663.

3 N. R. Baral and A. Shah, Appl. Microbiol. Biotechnol., 2014, 98, 9151-9172.

4 B. Du, L. N. Sharma, C. Becker, S. F. Chen, R. A. Mowery, G. P. van Walsum and C. K. Chambliss, Biotechnol. Bioeng., 2010, 107, 430-440.

5 S.-F. Chen, R. A. Mowery, V. A. Castleberry, G. P. van Walsum and C. K. Chambliss, J. Chromatogr. A, 2006, 1104, 54-61.

6 C. Luo, D. L. Brink and H. W. Blanch, Biomass Bioenergy, 2002, 22, 125-138.

7 S. Ando, I. Arai, K. Kiyoto and S. Hanai, J. Ferment. Technol., 1986, 64, 567-570.

8 T. Ezeji, N. Qureshi and H. P. Blaschek, Biotechnol. Bioeng., 2007, 97, 1460-1469.

9 D. H. Cho, Y. J. Lee, Y. Um, B.-I. Sang and Y. H. Kim, Appl. Microbiol. Biotechnol., 2009, 83, 1035-1043.

10 G.-L. Cao, N.-Q. Ren, A.-J. Wang, W.-Q. Guo, J.-F. Xu and B.-F. Liu, Int. J. Hydrogen Energy, 2010, 35, 13475-13480.

11 J. Zaldivar, A. Martinez and L. O. Ingram, Biotechnol. Bioeng., 1999, 65, 24-33.

12 J. Li, C. Zhu, M. Tu, P. Han and Y. Wu, Appl. Biochem. Biotechnol., 2015, 175, 3657-3672.

13 H. J. Heipieper, F. J. Weber, J. Sikkema, H. Keweloh and J. A. de Bont, Trends Biotechnol., 1994, 12, 409-415.

14 H. Keweloh, R. Diefenbach and H.-J. Rehm, Arch. Microbiol., 1991, 157, 49-53.

15 R. Perkins, H. Fang, W. Tong and W. J. Welsh, Environ. Toxicol. Chem., 2003, 22, 1666-1679.

$16 \mathrm{~W}$. Karcher and J. Devillers, Practical applications of quantitative structure-activity relationships (QSAR) in environmental chemistry and toxicology, Springer Science \& Business Media, 1990. 
17 C. L. Russom, S. P. Bradbury, S. J. Broderius, D. E. Hammermeister and R. A. Drummond, Environ. Toxicol. Chem., 1997, 16, 948-967.

18 C. Hansch and A. Leo, Substituent constants for correlation analysis in chemistry and biology, Wiley, 1979.

19 K. Chan, N. Jensen and P. J. O'Brien, J. Appl. Toxicol., 2008, 28, 608-620.

20 K. Chan, R. Poon and P. J. O'Brien, J. Appl. Toxicol., 2008, 28, 1027-1039.

21 Y. Zhang, B. Han and T. C. Ezeji, New Biotechnol., 2012, 29, 345-351.

22 E. Palmqvist, J. S. Almeida and B. Hahn-Hägerdal, Biotechnol. Bioeng., 1999, 62, 447-454.

23 H. B. Klinke, B. K. Ahring, A. S. Schmidt and A. B. Thomsen, Bioresour. Technol., 2002, 82, 15-26.

24 J. Fenske, D. Griffin and M. Penner, J. Ind. Microbiol. Biotechnol., 1998, 20, 364-368.
25 J. R. Almeida, T. Modig, A. Petersson, B. Hähn-Hägerdal, G. Lidén and M. F. Gorwa-Grauslund, J. Chem. Technol. Biotechnol., 2007, 82, 340-349.

26 R. Xie, M. B. Tu and T. Elder, Energy Fuels, 2016, 30, 30783084.

27 M. Friedman, P. R. Henika and R. E. Mandrell, J. Food Prot., 2003, 66, 1811-1821.

28 S. Larsson, A. Quintana-Sáinz, A. Reimann, N.-O. Nilvebrant and L. J. Jönsson, Appl. Biochem. Biotechnol., 2000, 84-86, 617-632.

29 S. Prescott and C. Dunn, Ind. Microbiol., 1959, 250-284.

30 M. G. N. Hartmanis, T. Klason and S. Gatenbeck, Appl. Microbiol. Biotechnol., 1984, 20, 66-71.

31 T. Ezeji, C. Milne, N. D. Price and H. P. Blaschek, Appl. Microbiol. Biotechnol., 2010, 85, 1697-1712.

32 M. T. D. Cronin and T. W. Schultz, Chem. Res. Toxicol., 2001, 14, 1284-1295. 